\title{
SUBJECTIVE INTERPRETATION OF CALORIC INDUCED VERTIGO IN ASYMPTOMATIC DIABETIC VERSUS NORMAL VOLUNTEERS:
}

\author{
$\mathscr{B g}$ \\ Ashraf Elsayed Morgan, \\ Elshahat Ibrahem Ismail Elshokry \\ and Dr. Wessam Ibrahim Elshawaf \\ From \\ From Audiology - ENT Department Faculty of Medicine, \\ Mansoura University.
}

\begin{abstract}
objectives: to evaluate if there is normal vestibular laboratory functions.

variability in subjective perception of vertigo in diabetic patients in comparison to non-diabetic subjects. Methods: 28 patients with diabetes type 2 and 28 normal volunteers participated in the present study. Monothermal cool caloric test used to induce vertigo and visual analog scale (VAS) used to quantify the intensity the perceived caloric induced vertigo. Results: there was no significant difference between both groups in all study variables. There was a significant difference in VAS scores between both ears in diabetic group patients. Conclusion: there is abnormal vestibular performance in diabetic patients even in the presence of

\section{INTRODUCTION}

Diabetes mellitus is one of the most common disease and defined as a chronic systemic disease, related to an absolute or relative insulin deficiency, manifested by a deficient insulin secretion by the pancreas and/or a deficient insulin action on the target tissue [1]. Such insulin action deficiency results in hyperglycemia causing abnormal carbohydrate, lipids, protein and other metabolic disorders [2], abnormal glucose metabolism can affects inner ear function resulting in auditory or vestibular disorders, or both [3].
\end{abstract}

MANSOURA MEDICAL JOURNAL 
194 TITLE: SUBJECTIVE INTERPRETATION OF CALORIC etc...

Human subjective interpretation frequency analogous to a $0.003 \mathrm{~Hz}$ and perception of the magnitude or angular movement [8]. Based on the intensity of vertigo and dizziness knowledge that the semicircular cainfluenced by several factors includ- nals can efficiently respond to anguing for example; patient's personali- lar movements at 1 to $6 \mathrm{~Hz}$, it may be ty, anxiety and fear of unpredictable concluded that present caloric test recurrence of symptoms, vertigo- evaluate vestibular system in a nonassociated symptoms as neuro- physiological frequency [9]. Howevvegetative and the unpredictable ev- er, caloric test is considered one of olution of the underlying disease. These factors that affect patients interpretation of vertigo as a symptom are all subjective. Therefore, subjective perception may be considered poorly linked and poorly correlated with objective assessment namely vestibular testing [4,5]. Agreement between patient's and physician's symptom assessment reported to be moderate for vertigo [6,7]. In this context, it is obvious that every patient quantifies his or her symptoms in different way. Accordingly, only patient's symptom assessment is not sufficient and the patient's perspective should be considered.

Caloric stimulation can be evoked either with water or air irrigation, stimulating mainly the lateral canal that generates vestibular nystagmus through vestibulo-ocular reflex at a the most informative tests in vestibular evaluation of any dizzy patient. It allows each labyrinth to be assessed independently and informs about side of lesion and characterization of its intensity $[10,11]$

Several vertigo questionnaires developed to address the impact of the patient's vertigo on daily activities without regarding how two patients may interpret and perceive the same vertigo intensity. Accordingly, the present study was designed to use a fixed stimulus namely the caloric test that induce vertigo to evaluate how patients can subjectively perceive and interpret caloric induced vertigo using simple visual analog scale (VAS) and address some inter-subject variability that may influence their subjective perception of vertigo.

Vol. 44, No. 1 \& 2 Jan. \& April, 2015 


\section{METHODS}

Twenty-eight volunteers with type 2 DM and 28 age matched volunteers with no DM recruited in the present study. None of the study subjects reported vertigo or dizziness suggestive of vestibular disease. Age of study group ranged between 21 and 77 years. Patients with external, middle ear problems or previous history of vertigo, neurological problems known to affect audiovestibular system, family history of hearing impairment, visual problems and ototoxic drug intake were excluded from this study.

All patients in the study subjected to the following:

1. Comprehensive history taking (including age, sex, previous history of vertigo);

2. Otoscopic examination to ensure intact tympanic membrane and that no wax or foreign body in the external auditory canal and

3. Monothermal caloric test.

Monothermal caloric test was done using VNG instrument from Micro medical, spectrum, visual eye, version 6.1 (USA). Patients instructed to stop vestibular suppressant drugs and sedative for three days and fast for sex hours before assessment.

The calibration of eye movements was done in the beginning of the test. When performing the caloric test, the subject was kept in supine position with the head tilted at $30^{\circ}$. Water irrigation was carried out in each ear separately starting with the right ear using $250 \mathrm{ml}$ water at $30^{\circ} \mathrm{C}$ for 40 seconds, with a five-minute interval between stimulations [12]. Patients were asked to perform mathematical calculation during caloric test for purpose of patient's distraction to avoid cortical inhibition of caloric induced response.

Slow phase velocity of caloric induced nystagmus used to measure caloric response and the patients were asked to point to a number from VAS that is approximately representative to the magnitude of the patient's perception of caloric induced vertigo. In VAS, patients estimate the intensity of their symptoms related to vertigo. The scale ranges from zero to ten; zero means that there is no perceived vertigo and ten being the greatest level of vertigo. 
STATISTICAL ANALYSIS

Data analyzed using statistical package for social science software computer program version 17 (SPSS, Inc., Chicago, IL, USA). Quantitative parametric data were presented in mean and standard deviation, while Quantitative nonparametric data were presented in median and interqurtile range (IQR). For quantitative parametric data, Student's t-test(Unpaired) was used to compare between two different groups and Student's t-test (Paired) to compare between two related groups while for quantitative nonparametric data, Mann Whitney was used to compare between two different groups and Wilcoxon signed rank test was used to compare between two related groups. Chisquare "X2" used to compare the qualitative data. Spearman correlation test used to assess correlation between variables. $P$ value less than 0.05 was considered statistically significant

\section{RESULTS}

Table 1. Descriptive analysis of study groups.

\begin{tabular}{|l|l|c|c|}
\hline \multicolumn{2}{|l|}{ Age (Mean \pm SD) } & 46.57 & \pm 12.45 \\
\hline \multirow{2}{*}{ Sex } & Male & 23 & $40.5 \%$ \\
\cline { 2 - 4 } & Female & 33 & $59.5 \%$ \\
\hline \multirow{2}{*}{$\begin{array}{l}\text { Study } \\
\text { groups }\end{array}$} & No DM & 28 & $66.7 \%$ \\
\cline { 2 - 4 } & Diabetic & 28 & $33.3 \%$ \\
\hline R Caloric (Mean \pm SD) & 28.0 & \pm 11.5 \\
\hline Lt Caloric (Mean \pm SD) & 25.9 & \pm 9.8 \\
\hline UW \% (Median-IQR) & 11.00 & $5.00-17.00$ \\
\hline R VAS score (Median-IQR) & 6.5 & $5.0-8.0$ \\
\hline L VSA score (Median-IQR) & 5.0 & $4.0-7.0$ \\
\hline
\end{tabular}

SD: standard deviation IQR: interquartile range

Vol. 44, No. 1 \& 2 Jan. \& April, 2015 
Table 2. Correlation between sex and scores of VSA in study group:

\begin{tabular}{|c|c|c|c|c|c|c|c|}
\hline & \multicolumn{6}{|c|}{ Sex } & \multirow{3}{*}{ P } \\
\cline { 2 - 7 } & \multicolumn{3}{|c|}{ Male } & \multicolumn{3}{c|}{ Female } & \\
\cline { 2 - 7 } & & Percentile & Percentile & & Percentile & Percentile \\
& Median & 25 & 75 & Median & 25 & 75 & \\
\hline R VAS & 6.0 & 5.0 & 8.0 & 8.0 & 5.0 & 8.0 & 0.27 \\
\hline L VAS & 5.0 & 4.0 & 7.0 & 6.0 & 5.0 & 7.0 & 0.5 \\
\hline
\end{tabular}

Table 2 showed no significant effect of sex on scores of VAS

Table 3. Comparison between diabetic and non-diabetic groups as regards age and sex.

\begin{tabular}{|l|l|r|r|r|r|r|}
\hline \multicolumn{2}{|c|}{ Items } & \multicolumn{2}{c|}{ Non-diabetic } & \multicolumn{2}{c|}{ DM } & \multicolumn{1}{c|}{ P } \\
\hline Age & 44.04 & \pm 13.92 & 51.64 & \pm 6.72 & 0.06 \\
\cline { 1 - 6 } Sex & Male & 12 & $42.9 \%$ & 10 & $35.7 \%$ & 0.65 \\
\cline { 2 - 6 } & Female & 16 & $57.1 \%$ & 18 & $64.3 \%$ & \\
\hline
\end{tabular}

Data expressed as mean $\pm S D$ or as frequency (Number-percent)

SD: standard deviation

$P *$ : significance $<0.05$

Table 3 showed no significant difference between both groups as regards age and sex.

Table 4. Comparison between diabetic and non-diabetic groups as regards caloric response (slow phase velocity of nystagmus)

\begin{tabular}{|l|r|r|r|r|r|}
\hline \multirow{2}{*}{ Items } & \multicolumn{2}{|c|}{ Non-diabetic } & \multicolumn{2}{c|}{ DM } & \multicolumn{1}{c|}{ P } \\
\cline { 2 - 5 } & Mean & \pm SD & Mean & \pm SD & \\
\hline R Caloric & 28.1 & 13.9 & 28.0 & 4.1 & 0.98 \\
\hline L Caloric & 24.5 & 11.0 & 28.6 & 6.5 & 0.2 \\
\hline
\end{tabular}

SD: standard deviation

$\mathrm{P} *$ : significance $<0.05$

Table 4 showed no significant difference between both groups as regards caloric response. 
Table 5. Comparison between diabetic and non-diabetic groups as regards caloric UW percentage, VAS scores.

\begin{tabular}{|l|c|c|c|c|r|}
\hline \multirow{2}{*}{\multicolumn{1}{|c|}{ Items }} & \multicolumn{2}{|c|}{ Non-diabetic } & \multicolumn{2}{c|}{ DM } & \multirow{2}{*}{ P } \\
\cline { 2 - 5 } & Median & IQR & Median & IQR & \\
\hline \multirow{2}{*}{ UW\% } & $12.00 \%$ & $7.00 \%-$ & $7.00 \%$ & $5.00 \%-$ & 0.056 \\
& & $22.00 \%$ & & $13.00 \%$ & \\
\hline R VAS score & 6.5 & $4.5-8.0$ & 6.5 & $5.0-8.0$ & 0.9 \\
\hline L VAS score & 6.0 & $3.0-8.0$ & 5.0 & $5.0-6.0$ & 0.68 \\
\hline
\end{tabular}

IQR: interquartile range $\mathrm{P}^{*}$ : significance $<0.05$

Table 5 showed no significant difference between both groups as regards caloric UW percentage and VAS scores.

Table 6. Comparison between slow phase velocities of nystagmus induced by right and left caloric test.

\begin{tabular}{|r|r|r|r|r|r|r|}
\hline \multirow{2}{*}{\multicolumn{2}{|c|}{ Items }} & \multicolumn{2}{c|}{ R Caloric } & \multicolumn{2}{c|}{ L Caloric } & \multirow{2}{*}{ P } \\
\cline { 2 - 6 } & Mean & \multicolumn{1}{c|}{ \pm SD } & Mean & \multicolumn{1}{c|}{ \pm SD } & \\
\hline \multirow{2}{*}{ DM } & No DM & 28.1 & 13.9 & 24.5 & 11.0 & 0.057 \\
\cline { 2 - 6 } & Diabetic & 28.0 & 4.1 & 28.6 & 6.5 & 0.65 \\
\hline
\end{tabular}

SD: standard deviation $\mathrm{P}^{*}$ : significance $<0.05$

Table 6 showed no significant difference between both groups as regards slow phase velocities of nystagmus of right and left caloric test. 
Table 7. Comparison between VAS scores in response to vertigo induced by right and left caloric test.

\begin{tabular}{|l|c|c|c|c|c|r|}
\hline \multirow{2}{*}{\multicolumn{2}{|c|}{ Items }} & \multicolumn{2}{c|}{ R VAS score } & \multicolumn{2}{c|}{ L VAS score } & \multirow{2}{*}{ P } \\
\cline { 3 - 6 } & Median & IQR & Median & IQR & \\
\hline \multirow{2}{*}{ DM } & No DM & 6.5 & $4.5-8.0$ & 6.0 & $3.0-8.0$ & 0.07 \\
\cline { 2 - 6 } & Diabetic & 6.5 & $5.0-8.0$ & 5.0 & $5.0-6.0$ & $0.002^{*}$ \\
\hline
\end{tabular}

IQR: interquartile range

$\mathrm{P} *$ : significance $<0.05$

Table 7 showed no significant difference between VAS scores in response to vertigo induced by right and left caloric test in non-diabetic group. A significant difference in VAS scores in response to vertigo induced by right and left caloric test obtained in diabetic group.

Table 8. Correlation of VAS scores in response to vertigo induced by right caloric test to slow phase velocities of nystagmus induce by right caloric test and age.

\begin{tabular}{|l|l|l|r|r|}
\hline \multicolumn{2}{|c|}{ Items } & \multicolumn{1}{c|}{ Rt C } & \multicolumn{1}{c|}{ Age } \\
\hline \multirow{2}{*}{ No DM } & \multirow{2}{*}{ R VAS score } & r & .192 & -.119 \\
\cline { 3 - 5 } & & P & .327 & .548 \\
\hline \multirow{2}{*}{ Diabetic } & \multirow{2}{*}{ R VAS score } & r & -.158 & .316 \\
\cline { 3 - 5 } & & P & .589 & .271 \\
\hline
\end{tabular}

r: Spearman correlation coefficient $\mathrm{P} *$ : significance $<0.05$

Table 8 showed no significant correlation between VAS scores in response to vertigo induced by right caloric test to slow phase velocities of nystagmus induced by right caloric test and age in both groups of study. 
Table 9. Correlation of VAS scores in response to vertigo induced by left caloric test to slow phase velocities of nystagmus induced by left caloric test and age.

\begin{tabular}{|l|l|l|r|r|}
\hline \multicolumn{2}{|c|}{ Items } & \multicolumn{1}{c|}{ Lt C } & \multicolumn{2}{c|}{ Age } \\
\hline \multirow{2}{*}{ No DM } & \multirow{2}{*}{ L VAS score } & R & -.187 & -.166 \\
\cline { 3 - 5 } & & $\mathrm{P}$ & .340 & .399 \\
\hline \multirow{2}{*}{ DM } & \multirow{2}{*}{ L VAS score } & $\mathrm{R}$ & -.478 & .455 \\
\cline { 4 - 5 } & & $\mathrm{P}$ & .084 & .102 \\
\hline
\end{tabular}

r: Spearman correlation coefficient $\mathrm{P} *$ : significance $<0.05$

Table 9 showed no significant correlation between VAS scores in response to vertigo induced by left caloric test to slow phase velocities of nystagmus induced by left caloric test and age in in both groups of study.

\section{DISCUSSION}

To the best of our knowledge, there was no previous studies evaluated subjective perception of vertigo among diabetic patients. At the laboratory levels, abnormal electronystagmography test results observed in some patients with type $1 \mathrm{DM}[13,14]$ but not all patients $[15,16]$ suggesting impaired SCC or superior vestibular nerve functions. In addition, impaired otoconial organ function measured by cervical or ocular VEMP has been reported [17]. In the present study, although caloric test is considered as a non-physiological test for evaluating the vestibular system, we choose it as fixed stimulus for inducing vertigo and then measure the output of this fixed stimulus.

Caloric test stimulates mainly the horizontal SCC and the low frequency response of the vestibular system. In all subjects of study group, there was no effect of sex of the subject of scores of VAS. The two study groups did not showed any significant difference in all variables of study. In the present study sample, there was no significant change in caloric response with age in both groups. In addition, VAS scores did not related to caloric response. $\mathrm{Pa}$ tients with DM showed significant intra-subject variability in their subjec-

Vol. 44, No. 1 \& 2 Jan. \& April, 2015 
tive perception of vertigo induced by caloric test measured by VAS although both ears did not significantly differed in slow phase velocities of nystagmus induced by the same stimulus. Type I vestibular hair cells known to have greater sensitivity to medication [18] and have increased likelihood of age-related degeneration [19].

Previous studies on SCC function in patients with DM reported abnormalities in few patients with type 2 DM, which may be explained by preservation the receptors that may be more responsive to such stimuli namely type 2 vestibular hair cells. Preservation of type 2 vestibular hair cells may explain our caloric response in patients with DM that did not differed from that of normal although there was different subjective perception of the response between both groups. This finding suggests abnormal patho-physiolocal effects of DM on the vestibular systems that may not detected by traditional methods. Because our target in the present study was to detect difference in subjective perception of vertigo in diabetic patients, we did not considered abnormal caloric re- sponse as the percentage of unilateral weakness in diabetic and its effects on subjective perception of vertigo. In addition, we used standard bithermal caloric and we did not consider the duration of the disease on VAS scores.

Therefore, we recommend another study that consider the missed issues in the present study which may spread our thinking on how subjective perception of vertigo differed among individuals.

\section{CONCLUSION}

The present study confirmed the previous findings of a higher incidence of abnormal vestibular performance in diabetic patients. In addition, there may be impaired vestibular performance in the presence of normal laboratory functions.

\section{REFERENCES}

[1] Sociedade Brasileira de Diabetes. (2005) : Disponível em: http://www.diabetes. org.br/ imprensa/ estatisticas/index.php\#Cal. Acessado em 20 de junho.

[2] Kuzuya T, Nakagawa S, Satoh MANSOURA MEDICAL JOURNAL 
TITLE: SUBJECTIVE INTERPRETATION OF CALORIC etc...

J et al. (2002) : Report of the Committee on the classification and diagnostic criteria of diabetes mellitus. Diabetes Res Clin Pract ;55(1):65- 85.

[3] Bittar RSM, Sanchez TG, Santoro PP, et al. (1998) : O metabolism da glicose e o ouvido interno. Arq Fund Otorrinolaringol; 2(1).

[4] Jacobson GP, Newman CW. (1990) : The development of the dizziness handicap inventory. Arch Otolaryngol Head Neck Surg; 116:424-7.

[5] Ventry I, Weinstein B. (1982) : The hearing handicap inventory for the elderly: a new tool. Ear Hear; 3:128-34.

[6] Suarez-Almazor ME, ConnerSpady B, Kendall CJ, et al. (2001) : Lack of congruence in the ratings of patients' health status by patients and their physicians. Med Decis Making ; 21:113-21.

Vol. 44, No. 1 \& 2 Jan. \& April, 2015
[7] Honrubia V, Bell TS, Harris MR, et al. (1996) : Quantitative evaluation of dizziness characteristics and impact on quality of life. Am J Otol; 17:595-602.

[8] Zajonk TP, Roland PS. ( 2005) : Vertigo and motion sickness. Part I: vestibular anatomy and physiology. Ear Nose Throat J; 84 (9):581-4.

[9] Tomlinson RD, Saunders GE, Schwartz DWF. (1980) : Analysis of human vestibulo-ocular reflex during active head movements. Acta Otola-ryngol; 90:184-90.

[10] Baloh RW, Furman JM. (1989) : Modern vestibular function testing. West $\mathrm{J}$ Med. ; 150(1):59-67.

[11] Ganança MM, Bottino MA, Bittar RSM, et al. (2009) : Reference standard to read the air-driven caloric reflex test results. Braz J Otorhinolaryngol. 2009;75(1):2.

[12] Tole JR. (1979) : A protocol for 
the air caloric test and a comparison with a standard water caloric test. Arch Otolaryngol. 05(6):314-9.

[13] Klagenberg KF, Zeigelboim $B S$, Jurkiewicz AL, et al. (2007) : Vestibulocochlear manifestations in patients with type I diabetes mellitus. Braz J Otorhinolaryngol. ; 73:353-358.

[14] Aantaa E, Lehtonen A. (1981) : Electronystagmographic findings in insulindependent diabetics. Acta Otolaryngol.; 91:15-18.

[15] Di Nardo W, Ghirlanda G, Cercone $S$, et al. (1999) : The use of dynamic posturography to detect neurosensorial disorder in IDDM without clinical neuropathy. J Diabetes Complications.; 13:79-85.

[16] Gawron W, Pospiech L, Orendorz-Fraczkowska $\mathrm{K}$, et al. (2002) : Are there any disturbances in vestibular organ of children and young adults with type I diabetes? Diabetologia. ; 45:728-734.

[17] Kamali B, Hajiabolhassan F, Fatahi J, et al. (2013) : Effects of diabetes mellitus type I with or without neuropathy on vestibular evoked myogenic potentials. Acta Med Iran. ; 51:107-112.

[18] Lyford-Pike S, Vogelheim C, Chu E, et al. (2007) : Gentamicin is primarily localized in vestibular type I hair cells after intratympanic administration. J Assoc Res Otolaryngol. ; 8:497-508.

[19] Rauch SD, VelazquezVillasenor L, Dimitri PS, et al. (2001) : Decreasing hair cell counts in aging humans. Ann N Y Acad Sci. ; 942:220-227. 